\title{
ADAPTABILIDADE E ESTABILIDADE DE COMPORTAMENTO DE CULTIVARES DE MILHO EM TREZE AMBIENTES NOS TABULEIROS COSTEIROS DO NORDESTE BRASILEIRO
}

\author{
HÉLIO WILSON LEMOS DE CARVALHO ${ }^{2}$, MANOEL XAVIER DOS SANTOS ${ }^{3}$, \\ MARIA DE LOURDES DA SILVA LEAL ${ }^{2}$, CLESO ANTONIO PATO PACHECO ${ }^{3}$ e JOSÉ NILDO TABOSA 4
}

\begin{abstract}
RESUMO - Dezesseis cultivares de milho foram avaliadas em treze ambientes dos tabuleiros costeiros do Nordeste brasileiro, no período de 1994/95, em blocos ao acaso, com três repetições, visando conhecer o potencial dessa região para a produção do milho e a adaptabilidade e a estabilidade desses materiais para recomendação. As produtividades médias alcançadas, especialmente com os híbridos, mostraram o grande potencial dessa faixa costeira do Nordeste para a produção do milho, sobressaindo os tabuleiros costeiros do Piauí, Sergipe e Bahia, onde o milho poderá se tornar uma grande alternativa para os produtores. A análise de variância conjunta mostrou diferenças entre os locais e as cultivares, e a inconsistência das cultivares em face das variações ambientais. Usou-se o método de Cruz et al. para atenuar o efeito da interação cultivares $\mathrm{x}$ ambientes, de modo a permitir uma recomendação com mais segurança. Os híbridos mostraram melhor adaptação que as variedades e populações, e são recomendados para exploração em ambientes mais tecnificados. O AG 510, por mostrar adaptação em ambiente desfavorável, é também recomendado para esta condição. As variedades BR 5011, BR 5028, BR 106 e BR 5033, de bons rendimentos, constituem alternativas importantes para pequenos e médios produtores de milho.
\end{abstract}

Termos para indexação: interação genótipos x ambientes, variedades, híbridos.

\section{ADAPTABILITY AND BEHAVIOUR STABILITY OF CORN CULTIVARS AT THIRTEEN ENVIRONMENTS OF BRAZILIAN NORTHEAST COASTAL TABLELAND}

\begin{abstract}
The potential of the Brazilian Northeast coastal tablelands for corn production and the adaptability and stability of sixteen corn cultivars were evaluated at thirteen environments of this region in 1994/95 on a randomized block design experiment with three replications. The large potential of this coastal strip for corn production was evidenced by the obtained yield, highlighting the hybrids, on the coastal tablelands of Piauí, Sergipe and Bahia States, where corn would become a major crop option for the growers. Pooled variance analysis showed significant difference for environments and cultivars, and the interactions environment $\mathrm{x}$ cultivar, which were inconsistent. Hybrids had better adaptation than varieties and populations; they are recommended for higher input situations. The AG 510 hybrid showed good adaptation to low and high input conditions, and therefore is recommended for both situations. The BR 5011, BR 5028, BR 106 and BR 5033 varieties had reasonable yields and are suitable for small and medium corn growers.
\end{abstract}

Index terms: interaction of genotype x environment, varieties, hybrids.

\footnotetext{
${ }^{1}$ Aceito para publicação em 13 de abril de 1999.

${ }^{2}$ Eng. Agr., M.Sc., Embrapa-Centro de Pesquisa Agropecuária dos Tabuleiros Costeiros (CPATC), Caixa Postal 44, CEP 49001-970 Aracaju, SE. E-mail: helio@cpatc.embrapa.br

${ }^{3}$ Eng. Agr., Ph.D., Embrapa-Centro Nacional de Pesquisa de Milho e Sorgo (CNPMS), Caixa Postal 151, CEP 35701-970 Sete Lagoas, MG

${ }^{4}$ Eng. Agr., M.Sc., IPA, Caixa Postal 1022, CEP 50761-100 Recife, PE
}

\section{INTRODUCÃO}

Os tabuleiros costeiros ocupam todo o litoral do Nordeste brasileiro; tem uma área estimada de 8,420 milhões de hectares, e neles se constata grande diversidade de solo e clima (Embrapa, 1994). Nessa região, tem-se observado um incremento considerável na demanda pelo milho, em razão da alta densidade demográfica e do crescente aumento da explo- 
ração de aves e suínos, tornando necessária até mesmo, a importação de grande quantidade de milho de outras partes do país e do exterior, para complementar a necessidade regional. Além do consumo humano, largamente utilizado, o seu consumo em granjas localizadas nos grandes centros urbanos da região, principalmente no Estado de Pernambuco, temse notado um aumento significativo de consumo de milho, o que contribuiu para aumentar a importação desse produto, em razão de a produção regional não ser suficiente para suprir à sua procura.

Por outro lado, os tabuleiros costeiros apresentam grande potencial para o desenvolvimento da cultura do milho, conforme se tem constatado em trabalhos de competição de cultivares realizados nos municípios de Nossa Senhora das Dores Neópolis (Carvalho \& Serpa, 1987; Carvalho, 1988; Carvalho et al., 1992) e nos municípios de Lagarto, Umbaúba, Neópolis e Nossa Senhora das Dores (Carvalho et al., 1996a, 1996b, 1997), localizados nos tabuleiros do Estado de Sergipe. De forma semelhante, resultados favoráveis ao desenvolvimento do milho em outras áreas dos tabuleiros foram também constatados por Carvalho et al. (1996b, 1997) e Cardoso et al. (1997), que registraram produtividades médias de até $7 \mathrm{t} / \mathrm{ha}$, ficando demonstrada também a superioridade dos híbridos em relação às variedades.

As superfícies dos tabuleiros são planas ou ligeiramente onduladas, e possuem solos que se prestam às práticas de agricultura mecanizada, tendo ainda como vantagens para a produção agrícola a constância da estação chuvosa, solos com uma profundidade de $2 \mathrm{~m}$ e isento de pedras, e localização nas proximidades de grandes centros consumidores.

Percebendo a vantagem de produzir milho nessa região, de acordo com os resultados favoráveis alcançados nos trabalhos citados, em que os híbridos e variedades mostraram bons rendimentos, avicultores e suinocultores dos Estados de Sergipe e Alagoas têm plantado, com sucesso, milho em áreas de pousio de cana-de-açúcar, onde foram atingidas produtividades médias de $6 \mathrm{t} / \mathrm{ha}$, com tecnologias modernas de produção, além de essa prática favorecer bastante o desenvolvimento de cana plantada em rotação. Vale salientar que no
Estado de Alagoas, os agricultores e suinocultores pretendem plantar $25 \%$ da área de pousio cana-deaçúcar (80.000 ha), com o milho, em razão do bom comportamento apresentado pela cultura, graças à proximidade do centro consumidor e à redução de custo no processo da importação.

Vale ressaltar, também, que parte significativa das pastagens dos tabuleiros costeiros estão em estádios de degradação; o milho pode ser utilizado na recuperação dessas pastagens, a exemplo do que vem ocorrendo em alguns locais do Brasil Central, reduzindo os custos da recuperação dessas pastagens. Outra grande vantagem do milho na região dos tabuleiros é a sua utilização como silagem, atividade essa que vem atingindo áreas significativas nos tabuleiros de Sergipe, para alimentação de gado leiteiro.

Nota-se, portanto, que apesar de nos tabuleiros prevalecerem as produções de gado de corte, de cana-de-açúcar, de cacau, de citros e de outras fruteiras, ocorrem também plantios significativos de mandioca, feijão e milho. Este último vem sendo explorado em toda a sua extensão, em pequenas áreas de produtores, mas com perspectivas de ser produzido em uma escala comercial mais ampla, a um custo de produção um pouco mais baixo ou equivalente aos custos correntes nas áreas tradicionais de produção de milho, com as vantagens de o produto ser produzido nas proximidades dos grandes centros consumidores, por reduzir os custos de importação, e em razão da maior garantia de produção, graças à constância do regime pluviométrico dessa região.

Este trabalho foi realizado com o objetivo de avaliar a adaptabilidade e a estabilidade de variedades, populações e híbridos de milho, quando submetidos a diferentes condições ambientais nos tabuleiros costeiros do Nordeste brasileiro.

\section{MATERIALE MÉTODOS}

As superfícies dos tabuleiros costeiros são planas ou ligeiramente onduladas, com solos de baixa fertilidade natural e baixa capacidade de retenção de cátions e água, com textura variando de argila arenosa a areia. A precipitação anual varia entre $500 \mathrm{~mm}$ a $1.500 \mathrm{~mm}$, sendo altamente sazonal, ocorrendo $80 \%$ dela no período de seis meses. As temperaturas anuais médias giram em torno de $26 \%$. 
Os ensaios foram instalados, em janeiro, nos municípios de Parnaíba (1994 e 1995), no Piauí; Maracanaú e Barreira (1994 e 1995), no Ceará, e Vitória de Santo Antão (1995), em Pernambuco. Em maio, foram realizados os plantios em Neópolis e Lagarto (1994 e 1995) e Umbaúba (1994), em Sergipe, e Cruz das Almas (1995), na Bahia. Nas áreas experimentais, os solos eram do tipo Areia Quartzosa (Parnaíba), aluviais (Maracanaú, Barreira e Neópolis), Podzólico Vermelho-Amarelo distrófico (Umbaúba) e Latossolo Vermelho-Amarelo distrófico (Lagarto, Cruz das Almas e Vitória de Santo Antão).

$\mathrm{Na}$ Tabela 1, constam os índices pluviais ( $\mathrm{mm}$ ) ocorridos durante o período experimental, com uma variação de $501 \mathrm{~mm}$, em Cruz das Almas, a 1.374 mm, em Barreira, bem como, as coordenadas geográficas de cada município, os quais estão compreendidos entre os paralelos $2^{\circ} 63^{\prime} \mathrm{S}$ e $12^{\circ} 40^{\prime} \mathrm{S}$ e $12^{\circ} 40^{\prime} \mathrm{S}$, englobando diferentes condições ambientais (Embrapa, 1994), onde foram realizados os experimentos

Foram utilizadas 16 cultivares de milho: Dina 766 (híbrido simples modificado); Zeneca 8447 e Braskalb XL 604 (híbridos duplos); Ag 510, Cargill 505, Cargill 805, Dina 170 e Germinal 85 (híbridos triplos); BR 106, BR 5011, BR 5028, BR 5033 e BR 5037 (variedades) e CMS 39, CMS 59 e CMS 50 (populações).

O delineamento experimental utilizado foi o de blocos ao acaso, com três repetições dos dezesseis tratamentos. Cada parcela constou de quatro fileiras de 5,0 $\mathrm{m}$ de comprimento, a espaços de $1,0 \mathrm{~m}$ entre fileiras e $0,50 \mathrm{~m}$ entre covas. Foram colocadas três sementes por cova, e foram deixadas duas plantas por cova após o desbaste. Foram colhidas as duas fileiras centrais de forma integral, correspondendo a uma área útil de $10,0 \mathrm{~m}^{2}$. Os ensaios de Parnaíba receberam adubação na quantidade de 80-70-30 kg/ha de $\mathrm{N}, \mathrm{P}_{2} \mathrm{O}_{5}$ e $\mathrm{K}_{2} \mathrm{O}$, respectivamente sob formas de uréia, superfosfato simples e cloreto de potássio, sendo todo o P e o K e 1/3 do N aplicados nos sulcos, na época do plantio, e o $\mathrm{N}$ restante, aplicado em cobertura, quando da emissão da oitava e da décima segunda folha. $\mathrm{O}$ ensaio de Maracanaú, em 1994, recebeu apenas uma adubação nitrogenada, em cobertura (40 dias após o plantio), usando-se $60 \mathrm{~kg} /$ ha de $\mathrm{N}$, na forma de uréia. No ensaio de 1995, nesse local, usaram-se $60 \mathrm{~kg} / \mathrm{ha}$ de $\mathrm{N}$, $80 \mathrm{~kg} /$ ha de $\mathrm{P}_{2} \mathrm{O}_{5}$ e $50 \mathrm{~kg} /$ ha de $\mathrm{K}_{2} \mathrm{O}$, nas formas de uréia, superfosfato simples e cloreto de potássio, sendo aplicado todo o $\mathrm{P}$ e o $\mathrm{K}$ na época do plantio, no fundo dos sulcos, e a uréia, em cobertura, aos 30 e 40 dias após a germinação. $\mathrm{O}$ ensaio de Barreira recebeu apenas uma adubação nitrogenada, semelhante à do ensaio de Maracanaú de 1994. Os ensaios de Vitória de Santo Antão,
Neópolis, Lagarto, Umbaúba e Cruz das Almas receberam uma adubação, usando-se $80 \mathrm{~kg} / \mathrm{ha}$ de $\mathrm{P}_{2} \mathrm{O}_{5} \mathrm{e}$ $60 \mathrm{~kg} / \mathrm{ha}$ de $\mathrm{N}$ nas formas de superfosfato simples e uréia, respectivamente. Todo o $\mathrm{P}$ foi aplicado por ocasião do plantio, no fundo dos sulcos, e o $\mathrm{N}$, em cobertura, na terceira e quinta semana, após o plantio.

O peso de grãos, em cada tratamento, após ser ajustado para o nível de $15 \%$ de umidade, foi submetido a uma análise de variância, por local, seguindo-se o modelo de blocos ao acaso. A seguir, realizou-se a análise de variância conjunta, com a finalidade de detectar a interação entre cultivares e ambientes. Os parâmetros de adaptabilidade e estabilidade foram determinados obedecendo-se à metodologia proposta por Cruz et al. (1989), a qual se baseia na análise de regressão bissegmentada, e tem como parâmetros de adaptabilidade a média $\left(\beta_{0 \mathrm{i}}\right)$ e resposta linear aos ambientes desfavoráveis $\left(\beta_{1 \mathrm{i}}\right)$ e aos ambientes favoráveis $\left(\beta_{1 \mathrm{i}}+\beta_{2 \mathrm{i}}\right)$; a estabilidade foi avaliada pelo desvio da regressão $\sigma_{\mathrm{ij}}$ de cada cultivar em função das variações ambientais.

Foi utilizado o seguinte modelo:

$\mathrm{Y}_{\mathrm{ij}}=\beta_{0 \mathrm{i}}+\beta_{1 \mathrm{i}} \mathrm{I}_{\mathrm{j}}+\beta_{2 \mathrm{i}} \mathrm{T}\left(\mathrm{I}_{\mathrm{j}}\right)+\delta_{\mathrm{ij}}+\bar{\xi}_{\mathrm{ij}}$ onde:

$\mathrm{Y}_{\mathrm{ij}}=$ média da cultivar i no ambiente $\mathrm{j} ; \mathrm{I}_{\mathrm{j}}=$ índice do ambiente; $\mathrm{T}\left(\mathrm{I}_{\mathrm{j}}\right)=0$ se $\mathrm{I}_{\mathrm{j}}<0 ; \mathrm{T}\left(\mathrm{I}_{\mathrm{j}}\right)=\mathrm{I}_{\mathrm{j}}-\overline{\mathrm{I}}_{+}$se Ij $>0$, sendo $\overline{\mathrm{I}}_{+}$a média dos índices $\mathrm{I}_{\mathrm{j}}$ positivos; $\beta_{0 \mathrm{i}}=$ média geral da cultivar $\mathrm{i} ; \beta_{1 \mathrm{i}}=$ coeficiente de regressão linear associado à variável $T\left(I_{j}\right) ; \beta_{2 i}=$ coeficiente de regressão linear associado à variável $\mathrm{T}\left(\mathrm{I}_{\mathrm{j}}\right) ; \delta_{\mathrm{ij}}=$ desvio da regressão linear; $\bar{\xi}_{\mathrm{ij}}=$ erro médio experimental.

\section{RESULTADOS E DISCUSSÃO}

Apesar de os tabuleiros costeiros mostrarem um período chuvoso constante (Embrapa, 1994), a precocidade assume, nessa região, importância significativa, em razão de favorecer a colheita de duas safras dentro de mesmo ano agrícola, especialmente na faixa compreendida entre os Estados da Bahia e Alagoas. Nessa faixa, com o período chuvoso compreendido entre os meses de março a setembro, podese iniciar um plantio de milho visando à produção de grãos ou de milho verde até junho, e um segundo plantio, com cultivares precoces, a exemplo da variedade BR 5037, na segunda quinzena de junho, visando à produção de grãos. Na Tabela 2 , nota-se que as cultivares necessitaram, em média, de 53 e 52 dias para atingirem a fase de florescimento masculino, nos anos de 1994 e 1995, respectivamente, desta- 
TABELA 1. Índices pluviais ( $\mathrm{mm}$ ) ocorridos durante o período experimental, e as coordenadas geográficas dos municípios. Tabuleiros costeiros do Nordeste brasileiro, 1994 e 1995.

\begin{tabular}{|c|c|c|c|c|c|c|c|c|c|c|c|c|}
\hline \multirow[t]{2}{*}{ Mês } & \multicolumn{5}{|c|}{1994} & \multicolumn{7}{|c|}{1995} \\
\hline & Parnaíba & $\begin{array}{l}\text { Mara- } \\
\text { canaú }\end{array}$ & Barreira Neópolis & Lagarto & Umbaúba & Parnaíba & $\begin{array}{l}\text { Mara- } \\
\text { canaú }\end{array}$ & Barreira & $\begin{array}{c}\text { Vitória de } \\
\text { Santo Antão }\end{array}$ & Neópolis & Lagarto & $\begin{array}{c}\text { Cruz } \\
\text { das Almas }\end{array}$ \\
\hline
\end{tabular}

\begin{tabular}{|c|c|c|c|c|c|c|c|c|c|c|c|c|c|}
\hline \multicolumn{14}{|c|}{ Índices pluviais } \\
\hline Janeiro & 173 & 104 & 68 & - & - & - & 20 & 62 & 113 & - & - & - & - \\
\hline Fevereiro & 193 & 150 & 165 & - & - & - & 306 & 164 & 172 & - & - & - & - \\
\hline Março & 200 & 245 & 448 & - & - & - & 177 & 207 & 306 & - & - & - & - \\
\hline Abril & 279 & 462 & 269 & - & - & - & 295 & 368 & 324 & - & - & - & - \\
\hline Maio & 276 & 221 & 424 & 150 & 190 & 160 & 270 & 404 & 88 & - & 141 & 92 & 97 \\
\hline Junho & - & - & - & 455 & 197 & 401 & - & - & - & - & 340 & 202 & 114 \\
\hline Julho & - & - & - & 250 & 210 & 176 & - & - & - & - & 230 & 155 & 130 \\
\hline Agosto & - & - & - & 59 & 49 & 104 & - & - & - & - & 98 & 115 & 58 \\
\hline Setembro & - & - & - & 51 & 92 & 162 & - & - & - & - & 48 & 48 & 102 \\
\hline Total & 1.121 & 1.182 & 1.374 & 965 & 738 & 1.003 & 1.068 & 1.205 & 1.003 & & 857 & 612 & 501 \\
\hline
\end{tabular}

Coordenadas geográficas

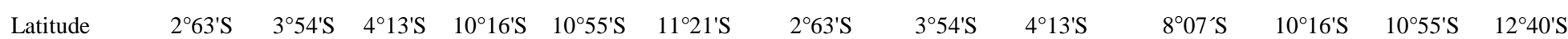
Longitude $\quad 41^{\circ} 41^{\prime} \mathrm{W} \quad 38^{\circ} 41^{\prime} \mathrm{W} 38^{\circ} 44^{\prime} \mathrm{W} \quad 36^{\circ} 51 \mathrm{~W} \quad 37^{\circ} 40^{\prime} \mathrm{W} \quad 37^{\circ} 40^{\prime} \mathrm{S} \quad 41^{\circ} 41^{\prime} \mathrm{W} \quad 38^{\circ} 41^{\prime} \mathrm{W} \quad 38^{\circ} 44^{\prime} \mathrm{W} \quad 35^{\circ} 18^{\prime} \mathrm{W} \quad 36^{\circ} 5 \mathrm{~W} \quad 37^{\circ} 40^{\prime} \mathrm{W} \quad 39^{\circ} 06^{\prime} \mathrm{W}$

\begin{tabular}{lllllllllllll} 
Altitude $(\mathrm{m})$ & 15 & 68 & 60 & 7 & 160 & 109 & 15 & 68 & 60 & 137 & 7 & 160 \\
\hline
\end{tabular}

Não foram registrados os índices pluviais neste município. 
cando-se a variedade BR 5037 como mais precoce, seguida das variedades BR 5033 e BR 5028 e da população CMS 50. Os híbridos mostraram melhor uniformidade quanto ao caráter, detectando-se uma variação de 51 a 55 dias para atingir essa fase.

As cultivares mostraram também uma redução de plantas na colheita (Tabela 2); obtiveram-se, na média geral, 38 e 37 plantas/parcela, o que corresponde a 38.000 e 37.000 plantas/ha, e registram-se reduções de 2.000 e 3.000 plantas/ha, respectivamente, nos anos de 1994 e 1995, em relação ao estande proposto (40.000 plantas/ha). A variedade BR 106 mostrou a maior redução no ano de 1995, o que refletiu negativamente no seu rendimento, no referido ano agrícola. Pela mesma razão, a população CMS 39 e a variedade BR 5028 também tiveram os rendimentos prejudicados.

Nas Tabelas 3 e 4 constam as produtividades médias de grãos e os resultados das análises de variância de todos os ensaios, detectando-se diferenças entre as cultivares a $1 \%$ de probabilidade, pelo teste $\mathrm{F}$. Os coeficientes de variação obtidos oscilaram de $8,4 \%$ a $18,9 \%$, conferindo boa precisão aos ensaios (Pimentel-Gomes, 1985). A média de produtividade nos ensaios variou de $2.550 \mathrm{~kg} / \mathrm{ha}$ em Barreira e $6.238 \mathrm{~kg} / \mathrm{ha}$ em Parnaíba, o que indica uma ampla faixa da variação nas condições ambientais, em que foram realizados os ensaios. Os municípios de Parnaíba, no Piauí, e Lagarto, em Sergipe, apresentaram melhores potencialidades para o desenvolvimento do milho, com produtividades médias de $5.890 \mathrm{k} / \mathrm{ha}$ e $5.416 \mathrm{~kg} / \mathrm{ha}$, nos dois anos agrícolas, seguidos de Maracanaú, no Ceará, com $4.236 \mathrm{~kg} / \mathrm{ha}$ (média de dois anos) e Cruz das Almas, na Bahia, com $4.481 \mathrm{~kg} / \mathrm{ha}$, destacando-se como os ambientes mais favoráveis para a exploração do milho. Vale ressaltar que os rendimentos médios, obtidos em Parnaíba, tanto com híbridos quanto com variedades e populações, colocam os tabuleiros do Piauí em condições de competir com a exploração do milho com as áreas de cerrados, com a vantagem de mostrar uma maior constância no período chuvoso, o que significa melhor garantia de safra.

Em Cruz das Almas, à semelhança de Lagarto, onde é significativa a exploração de citros e mandioca, as produtividades alcançadas com o milho

TABELA 2. Médias referentes à floração masculina e ao estande de colheita de 16 cultivares de milho. Tabuleiros costeiros da Região Nordeste do Brasil, 1994 e 1995.

\begin{tabular}{|c|c|c|c|c|}
\hline \multirow[t]{2}{*}{ Cultivar } & \multicolumn{2}{|c|}{$\begin{array}{c}\text { Floração masculina } \\
\text { (dias) }\end{array}$} & \multicolumn{2}{|c|}{$\begin{array}{c}\text { Estande } \\
\text { (plantas/parcela) }\end{array}$} \\
\hline & 1994 & 1995 & 1994 & 1995 \\
\hline AG 510 & 52 & 52 & 39 & 39 \\
\hline BR 106 & 56 & 55 & 39 & 30 \\
\hline BR 5011 & 54 & 53 & 37 & 36 \\
\hline BR 5028 & 52 & 52 & 37 & 35 \\
\hline BR 5033 & 51 & 51 & 38 & 36 \\
\hline BR 5037 & 48 & 47 & 38 & 36 \\
\hline Braskalb XL 604 & 54 & 53 & 38 & 38 \\
\hline Cargill 505 & 52 & 52 & 39 & 39 \\
\hline Cargill 805 & 52 & 50 & 38 & 40 \\
\hline CMS 39 & 54 & 54 & 37 & 35 \\
\hline CMS 59 & 53 & 52 & 37 & 37 \\
\hline CMS 50 & 52 & 51 & 37 & 39 \\
\hline Dina 170 & 55 & 54 & 37 & 37 \\
\hline Dina 766 & 53 & 52 & 36 & 39 \\
\hline Germinal 85 & 53 & 52 & 38 & 40 \\
\hline Zeneca 8447 & 53 & 51 & 38 & 37 \\
\hline Média & 53 & 52 & 38 & 37 \\
\hline
\end{tabular}


mostram o bom potencial dessa faixa para a produção desse cereal, criando mais uma alternativa importante para a agricultura regional. Os tabuleiros do Ceará mostram também bom potencial para o cultivo do milho, especialmente em Maracanaú, onde se obteve um melhor rendimento. Em Barreira, onde se usou apenas uma adubação nitrogenada, em cobertura, os rendimentos das cultivares foram menores na safra de 1994, registrando-se um acréscimo de $55 \%$ no ano de 1995 , mostrando também boa perspectiva para o desenvolvimento do milho. Em Vitória de Santo Antão, PE, apesar de apresentar uma atividade diferente (hortaliças sob irrigação) e relevo ondulado, o milho desponta como alternativa importante para a produção de milho verde e grãos, principalmente, em pequenas e médias propriedades onde o milho constitui, um componente importante do regime alimentar. Vale acrescentar que todos esses ensaios foram realizados sob regime de sequeiro.
A análise de variância conjunta (Tabela 5) mostrou diferenças significativas a $1 \%$ de probabilidade, pelo teste $\mathrm{F}$, no que tange aos efeitos de cultivares, ambientes e interação cultivares $\mathrm{x}$ ambientes, o que evidencia comportamento diferenciado entre as cultivares e os ambientes, além de apresentar inconsistência no comportamento das cultivares em face das variações ambientais, e da semelhança do ocorrido em outros trabalhos de competição de cultivares realizados na Região Nordeste do Brasil (Costa, 1976; Carvalho et al., 1992; Lira et al., 1993; Cardoso et al., 1997); isto justifica a necessidade de se efetuar um estudo mais detalhado dessa interação. Tratando-se de uma região relativamente extensa, a interação cultivar $\mathrm{x}$ ambiente assume papel preponderante na recomendação de cultivares, e é necessário minimizar o seu efeito, o que é possível através da identificação de cultivares com maior estabilidade fenotípica (Ramalho et al., 1993).

TABELA 3. Produtividade média de grãos (kg/ha), coeficiente de variação (\%), valores de $\mathrm{F}$ e quadrado médio residual obtidos em seis municípios, com 16 cultivares de milho. Tabuleiros costeiros do Nordeste, 1994.

\begin{tabular}{|c|c|c|c|c|c|c|}
\hline \multirow[t]{2}{*}{ Cultivar } & \multirow{2}{*}{$\begin{array}{c}\text { Piauí } \\
\text { Parnaíba }\end{array}$} & \multicolumn{2}{|c|}{ Ceará } & \multicolumn{3}{|c|}{ Sergipe } \\
\hline & & Maracanaú & Barreira & Lagarto & Umbaúba & Neópolis \\
\hline Braskalb XL 604 & 6.700 & 4.267 & 2.647 & 7.363 & 3.980 & 4.480 \\
\hline Dina 170 & 8.133 & 4.947 & 3.837 & 5.313 & 3.657 & 3.763 \\
\hline AG 510 & 6.900 & 4.917 & 3.400 & 3.897 & 3.823 & 4.630 \\
\hline Cargill 805 & 6.300 & 5.217 & 2.360 & 6.200 & 3.520 & 4.013 \\
\hline Germinal 85 & 6.533 & 4.183 & 2.693 & 5.320 & 3.673 & 4.383 \\
\hline BR 106 & 5.800 & 4.817 & 2.570 & 5.267 & 4.43 & 3.847 \\
\hline Zeneca 8447 & 6.133 & 4.633 & 2.140 & 5.843 & 4.277 & 3.210 \\
\hline BR 5011 & 5.300 & 4.333 & 1.890 & 5.193 & 4.187 & 3.773 \\
\hline CMS 39 & 6.400 & 4.750 & 2.830 & 5.300 & 2.893 & 2.503 \\
\hline Dina 766 & 6.100 & 4.500 & 2.440 & 5.593 & 2.093 & 3.937 \\
\hline BR 5033 & 5.567 & 4.000 & 2.410 & 4.870 & 3.777 & 3.407 \\
\hline BR 5028 & 5.200 & 3.640 & 2.107 & 4.740 & 3.300 & 3.293 \\
\hline CMS 59 & 6.400 & 3.823 & 2.550 & 3.557 & 3.020 & 2.627 \\
\hline Cargill 505 & 7.767 & 4.050 & 2.846 & 5.800 & 4.950 & 5.787 \\
\hline CMS 50 & 5.300 & 4.517 & 2.550 & 3.760 & 2.510 & 2.053 \\
\hline BR 5037 & 5.633 & 3.167 & 1.653 & 3.907 & 2.620 & 2.600 \\
\hline Média & 6.238 & 4.360 & 2.550 & 5.125 & 3.530 & 3.625 \\
\hline D.M.S (5\%) & 704 & 1.688 & 1.468 & 1.321 & 1.103 & 1.048 \\
\hline C.V. $(\%)$ & 11,7 & 12,7 & 18,9 & 8,4 & 10,3 & 9,5 \\
\hline $\mathrm{F}(\mathrm{T})$ & $3,9 * *$ & $2,8^{* *}$ & $3,4 * *$ & $15,7 * *$ & $12,8 * *$ & $23,8 * *$ \\
\hline Q.M. Residual & $53.576,4$ & $307.994,8$ & $232.721,2$ & $188.558,4$ & $131.469,0$ & $118.737,6$ \\
\hline
\end{tabular}


Em razão, portanto, da significância da interação cultivar $\mathrm{x}$ ambiente, foram verificadas as respostas de cada uma das cultivares nos ambientes considerados, pelo método proposto, o qual busca como cultivar ideal aquela que apresenta alta produtividade média, adaptabilidade em ambientes desfavoráveis $\left(b_{1}\right.$ o menor possível), e é capaz de responder às melhorias do ambiente $\left(b_{1}+b_{2}\right.$ o maior possível), além de apresentar a variância dos desvios da regressão próxima ou igual a zero.

A análise de estabilidade segundo o modelo proposto (Cruz et al., 1989) forneceu índices ambientais que variaram de -1.806 a 1.881 . Observou-se que a produtividade média $\left(\mathrm{b}_{0}\right)$ variou de $3.403 \mathrm{~kg} / \mathrm{ha}$ (BR 5037) a $5.252 \mathrm{~kg} / \mathrm{ha}$ (AG 510), com média geral de $4.356 \mathrm{~kg} / \mathrm{ha}$ (Tabela 6). Os híbridos mostraram melhor adaptação que as variedades, produzindo, em média, $4.887 \mathrm{~kg} / \mathrm{ha}$, superando em $21,7 \%$ a produtividade média das variedades e população (3.826 kg/ha). Os híbridos e as variedades BR 5011, BR 5033, BR 106 e BR 5028 e a população CMS 39 confirmaram o bom desempenho que têm manifestado em outros trabalhos realizados na região (Carvalho et al., 1996a, 1996b; Cardoso et al., 1997).

A estimativa de $b_{1}$ que avalia o desempenho das cultivares nos ambientes desfavoráveis, variou de 0,74 a 1,40, o que discrimina bem o comportamento das cultivares nessas condições (Tabela 6). Entre os híbridos, apenas o AG 510 mostrou ser mais estável nos ambientes desfavoráveis, e associou essa característica a uma alta produtividade média, o que torna desejável para utilização na região. Os híbridos Dina 170 e Zeneca 8447 mostraram ser muito exigentes, em virtude de apresentarem estimativas de $\mathrm{b}_{1}$ superiores à unidade, tendo, portanto, recomendação para ambientes mais ricos. Os demais híbridos

TABELA 4. Produtividade média de grãos (kg/ha), coeficiente de variação $(\%)$, valores de $F$, quadrado médio residual obtidos em sete municípios, com 16 cultivares de milho. Tabuleiros costeiros do Nordeste, 1995.

\begin{tabular}{|c|c|c|c|c|c|c|c|}
\hline \multirow[t]{2}{*}{ Cultivares } & \multirow{2}{*}{$\begin{array}{c}\text { Piauí } \\
\text { Parnaíba }\end{array}$} & \multicolumn{2}{|c|}{ Ceará } & \multirow{2}{*}{$\begin{array}{c}\begin{array}{c}\text { Pernam- } \\
\text { buco }\end{array} \\
\text { Vitória de } \\
\text { Santo Antão }\end{array}$} & \multicolumn{2}{|c|}{ Sergipe } & \multirow{2}{*}{$\begin{array}{c}\text { Bahia } \\
\text { Cruz das } \\
\text { Almas }\end{array}$} \\
\hline & & Maracanaú & Barreira & & Lagarto & Neópolis & \\
\hline AG 510 & 7.517 & 5.820 & 5.033 & 5.533 & 5.410 & 4.991 & 6.066 \\
\hline Dina 766 & 8.107 & 5.097 & 3.767 & 4.690 & 6.559 & 5.792 & 5.568 \\
\hline Braskalb XL 604 & 8.217 & 5.417 & 4.440 & 3.950 & 6.119 & 5.234 & 3.407 \\
\hline Cargill 505 & 6.837 & 4.303 & 4.780 & 3.307 & 6.656 & 4.533 & 6.305 \\
\hline Germinal 85 & 6.877 & 4.693 & 3.967 & 4.397 & 5.987 & 4.386 & 5.065 \\
\hline Dina 170 & 6.800 & 4.040 & 4.340 & 4.170 & 6.859 & 2.997 & 5.492 \\
\hline Zeneca 8447 & 6.590 & 3.897 & 4.000 & 2.483 & 7.666 & 4.118 & 4.955 \\
\hline Cargill 805 & 6.040 & 5.237 & 4.483 & 4.003 & 6.194 & 4.351 & 3.029 \\
\hline CMS 50 & 6.733 & 3.985 & 3.883 & 4.907 & 5.467 & 2.172 & 4.214 \\
\hline BR 5011 & 5.503 & 3.790 & 3.980 & 3.050 & 5.648 & 4.188 & 4.087 \\
\hline BR 5028 & 5.877 & 3.957 & 3.417 & 3.127 & 5.206 & 3.575 & 3.823 \\
\hline CMS 39 & 6.410 & 3.400 & 4.067 & 2.930 & 5.129 & 2.317 & 4.052 \\
\hline BR 5033 & 5.433 & 3.477 & 3.850 & 2.737 & 4.856 & 3.300 & 3.844 \\
\hline BR 5037 & 4.633 & 3.6 .33 & 3.283 & 2.977 & 4.391 & 3.129 & 3.095 \\
\hline BR 106 & 4.793 & 1.190 & 2.633 & 3.630 & 4.526 & 2.887 & 4.391 \\
\hline CMS 59 & 4.510 & 3.543 & 3.316 & 3.000 & 3.911 & 2.283 & 3.461 \\
\hline Média & 5.542 & 4.113 & 3.962 & 3.665 & 5.707 & 3.734 & 4.481 \\
\hline D.M.S (5\%) & 1.638 & 1.958 & 1.434 & 2.022 & 1.746 & 1.447 & 1.314 \\
\hline C.V. (\%) & 9,7 & 15,6 & 11,8 & 18,1 & 10,1 & 12,7 & 9,6 \\
\hline$F(T)$ & $11,00 * *$ & $8,8 * *$ & $5,1 * *$ & $5,6^{* *}$ & $8,8^{* *}$ & $16,0 * *$ & $16,1 * *$ \\
\hline Q.M. Residual & $289.830,4$ & $414.227,5$ & $222.008,2$ & $441.464,4$ & $329.344,9$ & $226.234,3$ & $186.541,1$ \\
\hline
\end{tabular}

** Significativo a $1 \%$ de probabilidade, pelo teste $\mathrm{F}$ 
mostraram adaptabilidade ampla $\left(\mathrm{b}_{1}=1\right)$, e associaram essa característica a bons rendimentos de grãos, justificando, portanto, as suas recomendações para a região.

A população CMS 59 foi a mais estável nos ambientes desfavoráveis $\left(\mathrm{b}_{1}<1\right)$ (Tabela 6$)$. No entanto, esse material apresentou rendimento médio abaixo da média geral, o que compromete a sua adaptabilidade nessas condições. As variedades BR 5011,
BR 5033, BR 106, BR 5028 e a população CMS 39, de rendimentos médios abaixo da média geral, mas superiores em relação à média de variedades e populações $(3.826 \mathrm{~kg} / \mathrm{ha})$, mostraram adaptabilidade ampla $\left(b_{1}=1\right)$. Carvalho et al. (1992) detectaram também adaptação ampla para as variedades BR 5028, BR 5011, BR 5037 e BR 5033. Cardoso et al. (1997) também obtiveram respostas semelhantes das variedades BR 5033 e BR 5011, encontrando, por outro

TABELA 5. Análise de variância conjunta para a produtividade de grãos de 16 cultivares de milho, em 13 ambientes nos tabuleiros costeiros do Nordeste brasileiro, no biênio 1994/95.

\begin{tabular}{lcc}
\hline Fonte de variação & Graus de liberdade & Quadrado médio \\
\hline Ambientes (A) & 12 & $51.741 .164,00^{* *}$ \\
Cultivares (C) & 15 & $14.066 .871,00^{* *}$ \\
Interação (AXC) & 180 & $1.434 .476,50^{* *}$ \\
Resíduo & 390 & $278.838,00$ \\
\hline
\end{tabular}

** Significativo a $1 \%$ de probabilidade pelo teste $\mathrm{F}$

TABELA 6. Produtividade média de grãos (kg/ha) e estimativas dos parâmetros de adaptabilidade e estabilidade de 16 cultivares de milho em 13 ambientes nos tabuleiros costeiros do Nordeste no biênio 1994/95. (Modelo de Cruz et al., 1989).

\begin{tabular}{|c|c|c|c|c|c|c|c|c|}
\hline \multirow[t]{2}{*}{ Cultivar } & \multicolumn{3}{|c|}{ Média nos ambientes } & \multirow[t]{2}{*}{$\mathrm{b}_{1}$} & \multirow[t]{2}{*}{$\mathrm{b}_{2}$} & \multirow[t]{2}{*}{$b_{1}+b_{2}$} & \multirow[t]{2}{*}{ Q. M. desvio } & \multirow[t]{2}{*}{$\mathrm{R}^{2}(\%)$} \\
\hline & Geral & Desfavorável & Favorável & & & & & \\
\hline AG 510 & 5.252 & 4.750 & 5.838 & $0,78 *$ & $0,10 \mathrm{~ns}$ & $0,88 \mathrm{~ns}$ & $2.434 .548,75^{++}$ & 87 \\
\hline Cargil 505 & 5.151 & 4.358 & 6.076 & $1,05 \mathrm{~ns}$ & $0,28 \mathrm{~ns}$ & $1,33 \mathrm{~ns}$ & $2.087 .159,62^{++}$ & 75 \\
\hline Braskalb XL 604 & 5.016 & 4.326 & 5.821 & $1,02 \mathrm{~ns}$ & $0,63 * *$ & $1,66 * *$ & $2.230 .144,75^{++}$ & 80 \\
\hline Dina 170 & 4.921 & 3.812 & 6.215 & $1,27 * *$ & $0,25 \mathrm{~ns}$ & $1,53 * *$ & $1.239 .618,37^{++}$ & 85 \\
\hline Cargill 805 & 4.781 & 4.045 & 5.640 & $1,09 \mathrm{~ns}$ & $0,14 \mathrm{~ns}$ & $1,24 \mathrm{~ns}$ & $1.567 .795,25^{++}$ & 76 \\
\hline Dina 766 & 4.746 & 3.974 & 5.647 & $1,11 \mathrm{~ns}$ & $-0,38 \mathrm{~ns}$ & $0,72 \mathrm{~ns}$ & $2.519 .804,50^{++}$ & 63 \\
\hline Germinal 85 & 4.741 & 4.024 & 5.579 & $0,98 \mathrm{~ns}$ & $0,15 \mathrm{~ns}$ & $1,14 \mathrm{~ns}$ & $363.1162,00 \mathrm{~ns}$ & 92 \\
\hline Zeneca 8447 & 4.489 & 3.387 & 5.775 & $1,40 * *$ & $-0,37 \mathrm{~ns}$ & $1,03 \mathrm{~ns}$ & $1.536 .652,00^{++}$ & 82 \\
\hline BR 5011 & 4.215 & 3.551 & 4.989 & $0,94 \mathrm{~ns}$ & $-0,20 \mathrm{~ns}$ & $0,74 \mathrm{~ns}$ & $651.677,18^{+}$ & 83 \\
\hline BR 5033 & 3.943 & 3.237 & 4.766 & $0,90 \mathrm{~ns}$ & $-0,14 \mathrm{~ns}$ & $0,76 \mathrm{~ns}$ & $421.580,40 \mathrm{~ns}$ & 88 \\
\hline CMS 39 & 3.938 & 2.990 & 5.041 & $1,12 \mathrm{~ns}$ & $-0,28 \mathrm{~ns}$ & $0,84 \mathrm{~ns}$ & $1.154 .064,00^{++}$ & 80 \\
\hline BR 106 & 3.921 & 2.983 & 5.016 & $1,00 \mathrm{~ns}$ & $-0,52 *$ & $0,47 * *$ & $3.040 .094,00^{++}$ & 51 \\
\hline BR 5028 & 3.881 & 3.258 & 4.607 & $0,89 \mathrm{~ns}$ & $0,06 \mathrm{~ns}$ & $0,92 \mathrm{~ns}$ & $196.098,20 \mathrm{~ns}$ & 94 \\
\hline CMS 50 & 3.799 & 3.152 & 4.554 & $0,85 \mathrm{~ns}$ & $-0,41^{*}$ & $0,44 * *$ & $2.433 .717,25^{++}$ & 50 \\
\hline CMS 59 & 3.505 & 2.960 & 4.204 & $0,74 \mathrm{~ns}^{* *}$ & $0,28 \mathrm{~ns}$ & $1,02 \mathrm{~ns}$ & $819.477,62^{++}$ & 76 \\
\hline BR 5037 & 3.403 & 2.802 & 4.106 & $0,86 \mathrm{~ns}$ & $0,42 *$ & $1,27 \mathrm{~ns}$ & $240.854,00 \mathrm{~ns}$ & 94 \\
\hline Média & 4.356 & & & & & & & \\
\hline C.V. (\%) & 12,1 & & & & & & & \\
\hline
\end{tabular}


lado, adaptação, a ambientes desfavoráveis, das BR 5028 e BR 5037. A variedade BR 106, apresentou, nesses trabalhos, rendimentos médios acima do geral e adaptação a ambientes favoráveis.

Os valores de $b_{1}+b_{2}$, que avaliam a resposta das cultivares nos ambientes favoráveis, mostrou que entre os híbridos apenas os Braskalb XL 604 e Dina 170 responderam à melhoria do ambiente $\left(b_{1}+b_{2}>1\right)$, sendo recomendados para ambientes onde é significativo o uso de insumos (Tabela 6). As variedades BR 106, BR 5037 e a população CMS 50 foram menos responsivos ao uso de insumos.

Com relação à estabilidade (Tabela 6), todos os híbridos, à exceção do Germinal 85 , mostraram os desvios da regressão significativamente diferentes de zero $\left(\sigma_{\text {di }}^{2} \neq 0\right)$, o que evidencia baixa estabilidade nos ambientes considerados, apesar de AG 510, Braskalb XL 604, Dina 170 e Zeneca 8447 apresentarem estimativas de $\mathrm{R}^{2}$ acima de $80 \%$, indicando um bom ajuntamento das retas de regressão, o que mostra que o grau de imprevisibilidade desses híbridos não deve ser prejudicado (Cruz et al., 1989). As variedades BR 5033, BR 5028 e BR 5037 mostraram boa estabilidade nos ambientes considerados $\left(\sigma_{\mathrm{di}}^{2}=0\right)$. A BR 5011 e a CMS 39, apesar de manifestarem baixa estabilidade $\left(\sigma_{\text {di }}^{2} \neq 0\right)$, apresentaram coeficientes de determinação superiores a $80 \%$, o que lhes confere bom aproveitamento do modelo proposto. A variedade BR 106 e as populações CMS 50 e CMS 59 mostraram comportamento imprevisível nos ambientes considerados $\left(\sigma_{\mathrm{di}}^{2} \neq 0\right)$. Usando a metodologia de Eberhart \& Russel (1966), Carvalho (1988) e Carvalho et al. (1992) encontraram respostas semelhantes nas variedades BR 5028, BR 5033 e BR 106. Com relação à BR 5011, Carvalho (1988), Carvalho et al. (1992), Lira et al. (1993) e Cardoso et al. (1997) detectaram comportamento previsível em todos os ambientes, discordando do resultado do presente trabalho. A variedade BR 5037 também mostrou comportamento discordante do encontrado por Carvalho (1988) e Carvalho et al. (1992) quando apresentaram comportamento imprevisível nos ambientes estudados. No entanto, o resultado obtido por Lira et al. (1993), com relação a esta variedade, no que diz respeito à estabilidade, foi semelhante ao do presente trabalho.
Considerando estes resultados e o grande potencial dos tabuleiros costeiros do Nordeste brasileiro para a produção de milho, pelas razões já apresentadas, deve-se, na recomendação dessas cultivares para exploração comercial na região, averiguar as condições prevalecentes em cada sistema de produção. Assim sendo, para uma agricultura mais tecnificada destacam-se os híbridos Braskalb XL 604 e Dina 170, por serem responsivos à melhoria ambiental. Os demais híbridos, apesar de não responderem ao uso de insumos $\left(b_{1}+b_{2}=1\right)$, por mostrarem boas produtividades, podem também ser recomendados para ambientes tecnificados. O AG 510, de maior produtividade média, apresenta também grande interesse para a região, por mostrar adaptação a ambiente menos tecnificado $\left(\mathrm{b}_{1}<1\right)$, e boa estabilidade nos ambientes considerados $\left(\mathrm{R}^{2}=87 \%\right)$, destacando-se, no conjunto avaliado, como o material mais próximo do material ideal proposto pelo modelo. As variedades BR 5011, BR 5033, BR 5028 e BR 106, de produtividades médias superiores à média das variedades e populações de adaptabilidade ampla têm as suas recomendações justificadas, por repetirem o bom comportamento produtivo apresentado em outros trabalhos de competição de cultivares na região (Carvalho, 1988; Carvalho et al., 1992; Cardoso et al., 1997); devem ser aconselhadas para pequenos e médios produtores, por terem limitação de capital, que lhes impede de investir em tecnologia moderna de produção, além de poderem reutilizar as sementes em plantios posteriores. A população CMS 39 mostra-se bastante promissora para a região, podendo tornar-se mais uma alternativa importante para os tabuleiros.

\section{CONCLUSÕES}

1. Os tabuleiros costeiros apresentam grande potencial para o desenvolvimento do milho, sobressaindo os tabuleiros do Piauí, Sergipe e Bahia como mais promissores

2. O híbrido pode ser utilizado para plantio nas grandes áreas de pousio da cana-de-açúcar, trazendo benefícios para o plantio posterior dessa cultura e maior rentabilidade para o produtor.

3. Os híbridos mostram melhor adaptação que as variedades e populações, superando-as em 27,7\%. 
4. O modelo utilizado permite efetuar uma recomendação das cultivares de acordo com o grau de tecnificação dos ambientes.

\section{REFERÊNCIAS}

CARDOSO, M.J.; CARVALHO, H.W.L. de; PACHECO, C.A.P.; SANTOS, M.X. dos; LEAL, M. de L. da S. Adaptabilidade e estabilidade de cultivares de milho no Estado do Piauí no biênio 1993/94. Revista Científica Rural, Bagé, v.2, n.1, p.35-44, 1997.

CARVAlHO, H.W.L. de. Comportamento de cultivares de milho no Estado de Sergipe. I - Ensaios de rendimentos, 1986 e 1987. Aracaju: EmbrapaCNPCo, 1988. 27p. (Embrapa-CNPCo. Boletim de Pesquisa, 3)

CARVALHO, H.W.L. de; MAGNAVACA, R.; LEAL, M.L. da S. Estabilidade de cultivares de milho no Estado de Sergipe. Pesquisa Agropecuária Brasileira, Brasília, v.27, n.7, p.1073-1082, 1992.

CARVALHO, H.W.L. de; SANTOS, M.X. dos; CARDOSO, M.J.; MONTEIRO, A.A.T.; TABOSA, J.N.; CARVALHO, P.C.L. de; LEAL, M. de L. da S. Recomendações de cultivares de milho para os tabuleiros costeiros do Nordeste. Aracaju: EmbrapaCPATC, 1996a. 9p. (Embrapa-CPATC. Comunicado técnico, 9).

CARVALHO, H.W.L. de; SANTOS, M.X. dos; LEAL, M. de L. da S. Cultivares de milho para os tabuleiros costeiros de Sergipe. Aracaju: EmbrapaCPATC, 1996b. 5p. (Embrapa-CPATC. Comunicado técnico, 6).

CARVALHO, H.W.L. de; SANTOS, M.X. dos; LEAL, M. de L. da S.; DONALD, E.R.C.; CARDOSO, M.J.; CARVALHO, B.C.L. de; SILVA, I.O.; MARQUES, H. da S.; CARVALHO, P.C.L. de; TABOSA, J.N.; BRITO, A.R.M.B.; LIRA, M.A.; MONTEIRO, A.A.T.; ANTERO NETO, J.F.;
ALBUQUERQUE, M.M.; ARANHA, W. da S. Cultivares de milho para o nordeste brasileiro: ensaios realizados no ano de 1996. Aracaju: EmbrapaCPATC, 1997. 8p. (Embrapa-CPATC. Comunicado técnico, 13).

CARVALHO, H.W.L. de; SERPA, J.E.S. Comportamento de cultivares de milho no Estado de Sergipe. Ensaios de rendimento, 1982, 1984 e 1985. Aracaju: Embrapa-CPATC, 1987. 32p. (Embrapa-CNPCo. Boletim de Pesquisa, 1)

COSTA, S.N. da. Interação de cultivares de milho (Zea mays $\mathrm{L}$.) $\mathrm{x}$ anos $\mathrm{x}$ localidades nos Estados do Piauí e do Maranhão-Brasil. Piracicaba: ESALQ, 1976. 82p. Tese de Mestrado.

CRUZ, C.D.; TORRES, R.A. de A.; VENCOVSKY, R. An alternative approach to the stability analysis proposed by Silva and Barreto. Revista Brasileira de Genética, v.12, n.12, n.3, p.567-580, 1989.

EBERHART, S.A.; RUSSEL, W.A. Stability parameters for comparing varieties. Crop Science, Madison, v.6, p.36-40, 1966.

EMBRAPA. Centro de Pesquisa Agropecuária dos Tabuleiros Costeiros (Aracaju, SE). Plano Diretor do Centro de Pesquisa Agropecuária dos Tabuleiros Costeiros (CPATC). Brasília: SPI, 1994. 37p.

LIRA, M.A.; LIMA, J.M.P. de; MEDEIROS FILHO, S.M.; GUERRA, A.G. Adaptabilidade de cultivares de milho no Rio Grande do Norte. Natal: EMPARN, 1993. 22p. (EMPARN. Boletim de Pesquisa, 23).

PIMENTEL-GOMES, F. Curso de Estatística Experimental. 8.ed. São Paulo: Nobel, 1985. 450p.

RAMALHO, M.A.P.; SANTOS, J.B. dos; ZIMMERMANN, M.J. de O. Interação dos genótipos x ambientes. In: RAMALHO, M.A.P.; SANTOS, J.B. dos; ZIMMERMAN, M.J. de O. Genética quantitativa em plantas autógamas aplicação no melhoramento do feijoeiro. Goiânia: UFG, 1993. Cap.6, p.131-169. (Publicação, 120). 